\title{
Toxicity and insect growth regulatory activities of medicinal plant, Withania somnifera, in flesh fly, Sarcophaga ruficornis (Diptera: Sarcophagidae)
}

\author{
Sandeep Kumar Gaur* and Krishna Kumar
}

\begin{abstract}
Background: The flesh fly Sarcophaga ruficornis is well known for its medical and veterinary importance in causing myiasis in humans and animals. The conventional use of chemical pesticides for controlling insect pests has resulted in environmental pollution besides posing serious hazards to non-target organisms and the development of pest resistance against these compounds. Considering the various harmful and adverse effects of chemical pesticides, an alternative and safe approach for the pest management has to be explored. The plant extracts derived from plants are eco-friendly in nature, easily biodegradable, and can be used as botanical pesticides.

Results: Extracts from root of the medicinal plant Withania somnifera were assessed for their toxicity and insect growth regulatory activity when administered to larvae of S. ruficornis. Topical administration of root extracts of $W$. somnifera to 0-3-day-old third instar larvae of S. ruficornis resulted into severe disruption of development, moulting, and metamorphosis producing several detrimental effects such as toxicity, prolongation of larval life, ecdysial stasis, abnormal pupariation, reduced normal pupariation and adult emergence, and development of pupal-adult mosaics and adultoids. The $L_{50}$ values in topical application of root extracts of $W$. somnifera were $28.19,43.49,47.48$, and $48.16 \mathrm{~g} / \mu \mathrm{L}$ against $\mathrm{S}$. ruficornis third instar day $0,1,2$, and 3 larvae, respectively.

Conclusion: These effects are similar to those observed as a consequence of the administration of juvenile hormone analogs (juvenoids) and may be due to interference with the normal hormonal mechanism of moulting and metamorphosis. This clearly demonstrates that the root extracts of $W$. somnifera may be used as an insect growth regulator for the control and management of S. ruficornis along with other bio-rational approaches in integrated pest management programs.
\end{abstract}

Keywords: Ashwagandha, Larval-pupal ecdysis, Pupal-adult mosaics, Abnormal pupariation, Adultoids, Flesh fly

\section{Background}

Myiasis is a parasitic infestation in vertebrates caused by dipteran insects which deposit their eggs or neonate larvae in the host's body or body apertures (Kaya et al. 2014) and the larvae can infect living or necrotic tissues involving the skin, nasopharynx, urogenital, and gastrointestinal tracts, feeding or living in necrotic host tissue,

\footnotetext{
* Correspondence: gaurs808@gmail.com

Department of Zoology, University of Allahabad, Prayagraj 211002, India
}

bodily fluids, or ingested food (Ly et al. 2018). Many insect species are involved in causing myiasis in humans and other animals, and are responsible for severe damage to animal husbandry resulting into significant economic loss including reduction of milk production, weight and fertility, and reduced hide quality (Francesconi and Lupi, 2012).

Sarcophaga ruficornis (Diptera: Sarcophagidae) (F., 1794), commonly known as flesh fly, is also a causative agent of human myiasis (Ferraz et al. 2010). Sarcophaga sp. has been
Springer Open
(C) The Author(s). 2020 Open Access This article is licensed under a Creative Commons Attribution 4.0 International License, which permits use, sharing, adaptation, distribution and reproduction in any medium or format, as long as you give appropriate credit to the original author(s) and the source, provide a link to the Creative Commons licence, and indicate if changes were made. The images or other third party material in this article are included in the article's Creative Commons licence, unless indicated otherwise in a credit line to the material. If material is not included in the article's Creative Commons licence and your intended use is not permitted by statutory regulation or exceeds the permitted use, you will need to obtain permission directly from the copyright holder. To view a copy of this licence, visit http://creativecommons.org/licenses/by/4.0/. 
reported to cause aural myiasis, nosocomial myiasis (Francesconi and Lupi, 2012), cutaneous myiasis (Kaya et al. 2014), wound myiasis (Ergun et al. 2016), intestinal myiasis (Ly et al. 2018), and neonatal myiasis (Martinez-Rojano et al. 2018). Sarcophaga sp. has also been reported to cause external myiasis in three cyprinid species like Cyprinus carpio, Barbus grypus, and Capoeta trutta caught from Atatürk Dam Lake, Turkey (Oktener and Alas, 2009). Apart from larvae of Sarcophaga sp causing myiasis, the adults may act as vectors for mechanical transmission of pathogens causing gastrointestinal diseases (Graczyk et al. 2005).

Unscrupulous and non-judicious use of chemical pesticides for control and management of insect pests has resulted in deleterious effects on the environment, ecosystem, and public health. Contamination of air, water, and soil has already adversely affected ecosystem and human health, disrupted the dynamics of the food web in the community, destroyed beneficial organisms, and led to the development of pest resistance (Zacharia, 2011). Considering these harmful effects of chemical pesticides, a safe and environmental friendly approach for insect control is desired. For instance, botanicals or compounds derived from the plants are considered to be the most convincing tool for the control and management of various insect pests (Pant et al. 2016). These plant derivatives are eco-friendly with target specificity, biodegradable, economically feasible, devoid of toxic residues, and with the least chances of development of pest resistance (Pant et al. 2016; Rajapakse et al. 2016).

Withania somnifera, commonly known as Aswagandha, is an important medicinal plant belonging to the Solanaceae family and widely used in the Indian traditional system of Ayurveda. The root of W. somnifera contains alkaloids (withanine, withasomnine, somniferine), steroidal lactone (withaferins and withanolides), and steroids (stigmasterol and sitoinosides). This medicinal herb has been shown to possess anti-microbial, anti-tumor, antiinflammatory, anti-stress, anti-diabetic, cardioprotective, and neuroprotective properties (Dar et al. 2015). The medicinal properties of root extracts of W. somnifera are very well known but its insecticidal and insect growth regulatory activity have been described only in a few lepidopteran and coleopteran insects (Gupta and Srivastava, 2008; Gaur and Kumar, 2017a, 2019; Yadav et al. 2019). In the present communication, the insect growth regulatory (IGR) activity of root extracts of $W$. somnifera against the dipteran flesh fly, S. ruficornis has been described.

\section{Materials and methods Insect rearing}

Sarcophaga ruficornis was reared according to the method of Singh and Kumar (2015c). Adults of $S$. ruficornis were captured from wild and kept at a ratio of $1 \delta^{\lambda}: 29$ in acrylic frame cages $(15 \times 15 \times 15 \mathrm{~cm})$ with gauze sides and provided with sugar powder and 10\% honey-water solution on a cotton pad for feeding. The adult flies were reared in the laboratory at $28 \pm 2{ }^{\circ} \mathrm{C}, 70$ $\pm 5 \%$ relative humidity and $10 \mathrm{~L}: 14 \mathrm{D}$ photoperiod to obtain a pure line colony. Fresh pieces of goat's liver were supplied as a standard protein source and also for larviposition. First instar, neonate larvae from a single female were collected and transferred to sterilized glass beakers containing fresh pieces of goat's liver for feeding. In order to prevent infection by the decomposition and spoilage of liver pieces due to bacterial infestation, fresh pieces of goat's liver were supplied daily to developing larvae which were shifted to clean and sterilized glass beakers. When the last instar larvae reached the post-feeding stage, they were transferred to sterilized glass troughs containing sawdust for pupariation. The pupation followed a few hours later and the pupal period lasted for 9-11 days at the end of which adult flies emerged.

\section{Plant material and extraction}

A pure herbal root powder product of W. somnifera was purchased from Sri Jain Ayurvedic Pharmacy, Kattedan, Hyderabad, India (Mfg. License No.T-1633/Ayur). The root extract of W. somnifera was prepared according to the method described by Rathi and Gopalakrishnan (2006). Two hundred fifty grams of root powder was extracted with $500 \mathrm{~mL}$ (boiling point $40-60{ }^{\circ} \mathrm{C}$ ) of acetone using a Soxhlet apparatus at $50{ }^{\circ} \mathrm{C}$ for two days and filtered through Whatman no. 1 filter paper. The acetone was removed with the help of a rotatory vacuum evaporator under reduced pressure at 22-26 $\mathrm{mmHg}$ and a crude extract of roots of W. somnifera was obtained. Known quantities of the crude extract were weighed and dissolved in $1 \mathrm{~mL}$ of acetone to get the desired concentrations or doses. For each treatment, fresh doses were prepared and stored at $4{ }^{\circ} \mathrm{C}$ to avoid differences in concentration due to evaporation.

\section{Experimental procedure}

The larvae of the desired age group, i.e., third instar day 0 (freshly moulted or $0-2 \mathrm{~h}$ old), 1,2 , and 3 were selected from the stock and grouped into batches of 15 larvae each. All experiments of one set were carried out on the larvae from a single batch to avoid any age difference. In separate set of experiments, the larvae were topically treated with different doses of root extracts of $W$. somnifera $(5,10,15$, and $20 \mu \mathrm{g} / 1 \mu \mathrm{L} / \mathrm{larva})$ applied on the dorsum of the posterior abdomen with the help of a microapplicator. The control larvae were treated with pure acetone only in a similar manner. After treatment, both treated and control larvae were transferred to sterilized beakers and provided with fresh pieces of goat's liver for feeding and subsequently post-feeding larvae 
were transferred to sawdust for pupariation. All the experiments were repeated thrice. Both the control and treated larvae were monitored regularly and dead, malformed specimens were fixed in Bouin's fluid and preserved in 70\% ethyl alcohol for morphogenetic studies. Photography was done using Nikon SMZ 1000 Binocular Stereozoom microscope and NIS Software (Towa Optics, Japan).

\section{Statistical analysis}

The data regarding larval-pupal ecdysis was subjected to one way ANOVA to find out a significant difference between the mean larval duration of treated and control groups. Correlation coefficient was also calculated to determine the correlation between the doses administered and various morphological abnormalities observed. The $\mathrm{LC}_{50}$ values were also analyzed. All the calculations were performed with the help of GraphPad Prism 2007, 5.01 software (San Diego, CA).

\section{Results}

Topical administration of different doses of root extracts of $W$. somnifera to third instar day 0 (freshly moulted or $0-2 \mathrm{~h}$ old), 1, 2, and 3 larvae of $S$. ruficornis resulted into larval and pupal mortality, delay in larval-pupal ecdysis, abnormal pupariation, suppression of adult emergence, and formation of pupal-adult mosaics and adultoids.

\section{Mortality}

Topical administration of root extracts of W. somnifera to third instar 0-3-day-old larvae of S. ruficornis resulted into larval and pupal mortality in a dose-dependent manner showing a significant positive correlation in all the treated groups (Table 1). Maximum larval and pupal mortality occurred as a result of treatment of third instar day 0 larvae and third instar day 3 larvae of S. ruficornis respectively (Table 1 ). The $\mathrm{LC}_{50}$ values of root extracts of $W$. somnifera were $28.19,43.49,47.48$, and $48.16 \mu \mathrm{g} /$ $\mu \mathrm{L}$ against $S$. ruficornis third instar days $0,1,2$, and 3 larvae, respectively (Fig. 1).

\section{Larval-pupal ecdysis duration}

Topical administration of root extracts of W. somnifera to 0-3-day third instar larvae of S. ruficornis resulted in a significant delay in larval-pupal ecdysis in a dosedependent manner as compared to controls (Fig. 2). The larval duration was increased significantly at all the doses as a result of treatment of 0 - and 1-day old third instar larvae of S. ruficornis (Fig. 2a, b) whereas in case of day 2- and day 3-old third instar larvae there was a significant prolongation of larval duration at higher doses of 15 and $20 \mu \mathrm{g} / \mu \mathrm{L}$ (Fig. 2c, d). There was a maximum prolongation of larval life of 1.81 days $(F=8.664$; $\left.R^{2}=0.2241 ; \mathrm{df}=4,120 ; p \leq 0.001\right), 1.01$ days $(F=5.875$;
$\left.R^{2}=0.1464 ; \mathrm{df}=4,137 ; p \leq 0.001\right), 0.86$ days $(F=4.165 ;$ $\left.R^{2}=0.1077 ; \mathrm{df}=4,138 ; p \leq 0.01\right)$, and 0.48 days $(F=$ $\left.3.481 ; R^{2}=0.0893 ; \mathrm{df}=4,142 ; p \leq 0.05\right)$ at a dose of 20 $\mu \mathrm{g} / \mu \mathrm{L}$ when $S$. ruficornis third instar day 0 , day 1 , day 2 , and day 3 larvae were respectively treated with root extracts of W. somnifera as compared to controls.

\section{Abnormal pupariation}

Topical administration of root extracts of W. somnifera to third instar 0-3-day-old larvae of S. ruficornis resulted in the formation of abnormal puparia in a dose-dependent manner (Table 1). There was a significant positive correlation between the doses applied and formation of abnormal puparia in case of treatment of day $0(r=0.99)$, day $1(r=0.95)$, day $2(r=$ $0.97)$, and day $3(r=0.95)$ third instar larvae (Table 1$)$. Production of abnormal puparia also increased with the increase in age of treated third instar larvae of $S$. ruficornis. Thus, abnormal puparia formation was dose-dependent as well as age-dependent.

Depending upon the abnormalities, abnormal puparia have been broadly classified into the following types:

(1) Body larval in appearance with coarse body surface and black-brown pupal pigmentation. The retraction of the anterior end has occurred but not fully complete whereas the longitudinal muscle contraction and cuticular shrinkage were inhibited (Plate 1C). In some cases, the larval body was extremely elongated with dark brown pupal pigmentation (Plate 1D).

(2) Contracted puparium showing brown pupal pigmentation. The anterior end has not fully retracted and the longitudinal muscle contraction and cuticular shrinkage adversely affected (Plate $1 \mathrm{E})$.

(3) Highly deformed and twisted puparium with dark brown pupal pigmentation and coarse body surface; the anterior end partially retracted but the longitudinal muscle contraction and cuticular shrinkage adversely affected. The whole body was tanned and sclerotized but the posterior end, especially the posterior extremity of the body remained untanned (white) and unsclerotized (Plate 1F).

(4) Elongated larval body suffering from inhibition of longitudinal muscle contraction which was more conspicuous towards the anterior end. The smooth body surface with brown pupal pigmentation was suggestive of cuticular shrinkage but the anterior end of the body not fully retracted (Plate 1G).

(5) Puparium larval in appearance with light brown pupal pigmentation having coarse body surface and 
Table 1 Effect of topical administration of root extracts of Withania somnifera to third instar day 0-3 larvae of Sarcophaga ruficornis $(n=15$; replication $=3)$

\begin{tabular}{|c|c|c|c|c|c|c|c|c|}
\hline \multirow[t]{2}{*}{ Age of larvae } & \multirow[t]{2}{*}{$\begin{array}{l}\text { Dose } \\
\left(\mu g \cdot \mu L^{-1}\right)\end{array}$} & \multirow{2}{*}{$\begin{array}{l}\text { Larval } \\
\text { mortality } \\
(\%)\end{array}$} & \multirow{2}{*}{$\begin{array}{l}\text { Abnormal } \\
\text { pupariation } \\
(\%)\end{array}$} & \multirow[t]{2}{*}{ Normal pupariation (\%) } & \multirow{2}{*}{$\begin{array}{l}\text { Pupal } \\
\text { mortality } \\
(\%)\end{array}$} & \multirow{2}{*}{$\begin{array}{l}\text { Pupal-adult } \\
\text { mosaics } \\
(\%)\end{array}$} & \multicolumn{2}{|c|}{$\begin{array}{l}\text { Adult emergence } \\
\text { (\%) }\end{array}$} \\
\hline & & & & & & & $\begin{array}{l}\text { Normal } \\
\text { adults } \\
(\%) \\
\end{array}$ & $\begin{array}{l}\text { Adultoids } \\
(\%)\end{array}$ \\
\hline \multirow[t]{6}{*}{ Third instar day 0} & 0 & 0 & 0 & 100 & 0 & 0 & 100 & 0 \\
\hline & 5 & 22.22 & 11.11 & 66.66 & 8.88 & 31.11 & 13.33 & 13.33 \\
\hline & 10 & 31.11 & 15.55 & 53.33 & 13.33 & 22.22 & 11.11 & 6.66 \\
\hline & 15 & 37.77 & 26.66 & 35.55 & 17.77 & 6.66 & 4.44 & 6.66 \\
\hline & 20 & 44.44 & 33.33 & 22.22 & 20.00 & 0.00 & 0.00 & 2.22 \\
\hline & & $(r=0.96)^{c}$ & $(r=0.99)^{a}$ & $(r=-0.98)^{b}$ & $(r=0.97)^{\mathrm{b}}$ & $(r=-0.28)$ & $(r=-0.79)$ & $(r=-0.07)$ \\
\hline \multirow[t]{6}{*}{ Third instar day 1} & 0 & 0 & 0 & 100 & 0 & 0 & 100 & 0 \\
\hline & 5 & 15.55 & 15.55 & 68.88 & 11.11 & 24.44 & 20.00 & 15.55 \\
\hline & 10 & 22.22 & 15.55 & 62.22 & 13.33 & 24.44 & 11.11 & 15.55 \\
\hline & 15 & 28.88 & 22.22 & 48.88 & 17.77 & 20.00 & 4.44 & 6.66 \\
\hline & 20 & 35.55 & 28.88 & 35.55 & 22.22 & 2.22 & 0.00 & 11.11 \\
\hline & & $(r=0.98)^{b}$ & $(r=0.95)^{c}$ & $(r=-0.97)^{\mathrm{b}}$ & $(r=0.97)^{\mathrm{b}}$ & $(r=-0.00)$ & $(r=-0.82)$ & $(r=0.32)$ \\
\hline \multirow[t]{6}{*}{ Third instar day 2} & 0 & 0 & 0 & 100 & 0 & 0 & 100 & 0 \\
\hline & 5 & 8.88 & 17.77 & 71.11 & 13.33 & 24.44 & 20.00 & 15.55 \\
\hline & 10 & 15.55 & 17.77 & 66.66 & 20.00 & 20.00 & 11.11 & 15.55 \\
\hline & 15 & 22.22 & 31.11 & 46.66 & 22.22 & 13.33 & 4.44 & 6.66 \\
\hline & 20 & 28.88 & 37.77 & 33.33 & 24.44 & 2.22 & 0.00 & 4.44 \\
\hline & & $(r=1.0)^{a}$ & $(r=0.97)^{b}$ & $(r=-0.98)^{b}$ & $(r=0.93)^{c}$ & $(r=-0.10)$ & $(r=-0.82)$ & $(r=-0.0002)$ \\
\hline \multirow[t]{6}{*}{ Third instar day 3} & 0 & 0 & 0 & 100 & 0 & 0 & 100 & 0 \\
\hline & 5 & 4.44 & 22.22 & 73.33 & 15.55 & 28.88 & 15.55 & 13.33 \\
\hline & 10 & 8.88 & 24.44 & 66.66 & 20.00 & 20.00 & 13.33 & 13.33 \\
\hline & 15 & 15.55 & 35.55 & 48.88 & 22.22 & 6.66 & 8.88 & 11.11 \\
\hline & 20 & 22.22 & 40.00 & 37.77 & 24.44 & 0.00 & 0.00 & 13.33 \\
\hline & & $(r=0.99)^{a}$ & $(r=0.95)^{c}$ & $(r=-0.98)^{b}$ & $(r=0.90) \mathrm{a}$ & $(r=-0.27)$ & $(r=-0.80)$ & $(r=0.67)$ \\
\hline
\end{tabular}

${ }^{\text {a Significant at } p \leq 0.001}$

${ }^{\mathrm{b}}$ Significant at $p \leq 0.01$

'Significant at $p \leq 0.05 ; r=$ correlation coefficient

failure of retraction of anterior segments (Plate $1 \mathrm{H}$ and I).

(6) Abnormal puparium with smooth body surface and brown pupal pigmentation but the body was unusual in not acquiring the typical barrel-shaped structure and thus suffering from inhibition of longitudinal muscle contraction (Plate 1J).

\section{Normal pupariation}

Normal pupariation was reduced in a dose-dependent manner as a result of topical administration of root extracts of $W$. somnifera to third instar day 0-3 larvae of $S$. ruficornis as compared to controls (Table 1). Maximum reduction in normal pupariation was observed at a dose of $20 \mu \mathrm{g} / \mu \mathrm{L}$ root extracts of $W$. somnifera. At this dose, 22.22, 35.55, 33.33, and 37.77\% normal puparia were formed as a result of treatment of third instar day 0 , day 1 , day 2 , and day 3 larvae respectively (Table 1 ). There was a significant negative correlation between the doses administered and percentage of normal pupariation in all the age groups of treated third instar larvae viz. day $0(r=-0.98)$, day $1(r=-0.97)$, day $2(r=-0.98)$, and day $3(r=-0.98)$ (Table 1$)$.

\section{Pupal-adult mosaics}

Topical administration of root extracts of W. somnifera to 0-3-day third instar larvae of S. ruficornis resulted into the formation of pupal-adult mosaics at all the doses except at $20 \mu \mathrm{g} / \mu \mathrm{L}$ as a result of treatment of third instar day 0 and day 3 larvae of S. ruficornis (Table 1). 


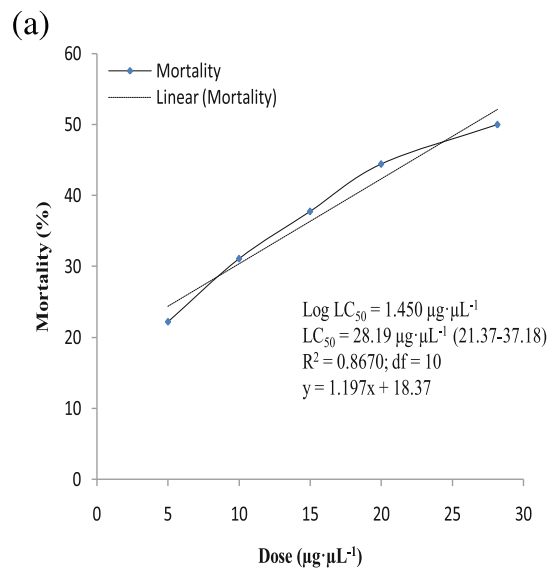

(c)

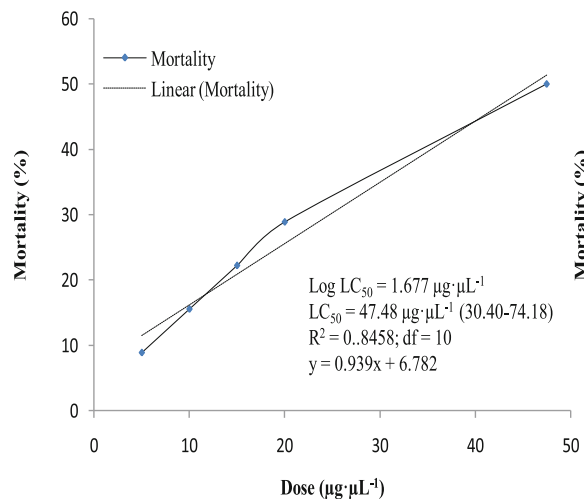

(b)

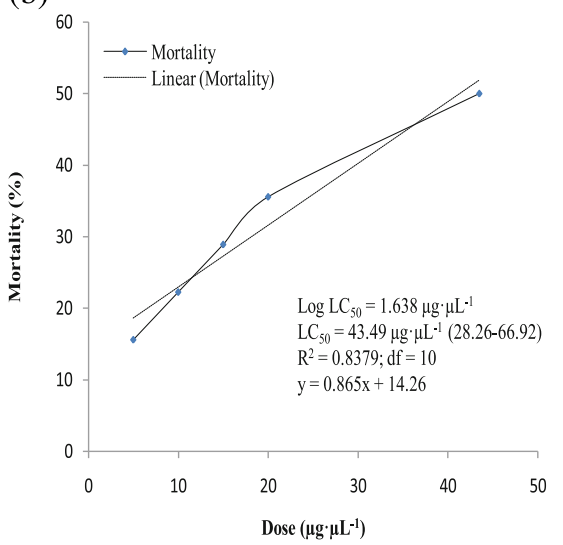

(d)

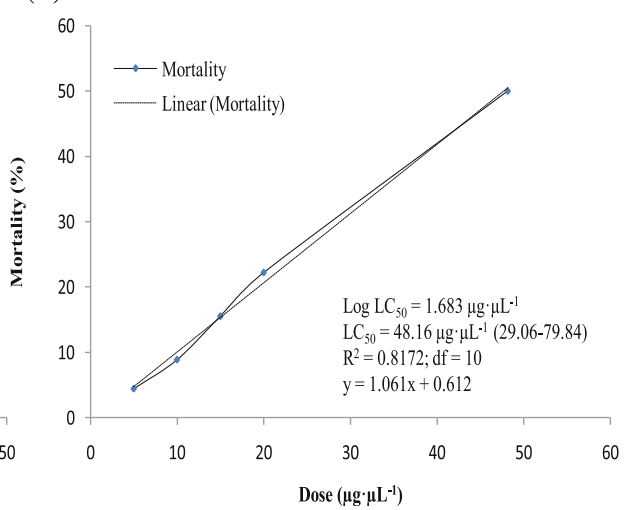

Fig. 1 Dose-mortality $\left(L C_{50}\right)$ response to root extracts of $W$. somnifera against a third instar day $0, \mathbf{b}$ third instar day $1, \mathbf{c}$ third instar day 2, and $\mathbf{d}$ third instar day 3 larvae of S. ruficornis. $\left(R^{2}=\right.$ coefficient of determination; $\mathrm{df}=$ degree of freedom)

Depending upon the development of pupal/adult characters, these have been broadly classified into the following grades;

(I) Body differentiated into head, thorax, and abdomen; whole body white, smooth, and pupal in appearance devoid of adult cuticle with hairs and bristles; mouthparts in the form of a protuberance; wings cylindrical; genitalia undeveloped (Plate $1 \mathrm{~K}$ and $\mathrm{L}$ ).

(II) Pupal-adult mosaic similar to grade (I) except tanning occurred partially in legs, wings, and mouthparts (Plate $1 \mathrm{M}$ and $\mathrm{N}$ ).

(III) Pupal-adult mosaic with pigmented eyes, ocelli partially developed; partially tanned left pro, meso, and meta and, right metathoracic legs and, rightwing whereas the rest characters pupal in appearance (Plate $1 \mathrm{O}$ and $\mathrm{P}$ ).

(IV) Pupal-adult mosaic consisting of untanned pupal head and thorax whereas the dorsal surface of abdomen highly tanned bearing small hairs and with inconspicuous adult segmentation; partially tanned legs and wings; ventral abdomen white and pupal devoid of genitalia (Plate $1 \mathrm{Q}$ and R).
(V) Pupal-adult mosaic with white, untanned pupal thorax; eyes pigmented; dorsal abdomen highly tanned and bearing small hairs; antennae, mouthparts, legs, and wings partially tanned; ventral abdomen white and devoid of genitalia (Plate 2A and B).

(VI) Pupal-adult mosaic with adult characteristics except for white, untanned and smooth pupal abdomen; genitalia undeveloped (Plate $2 \mathrm{C}$ and D).

(VII) Pupal-adult mosaic with adult characters but with less sclerotization and reduced numbers of hairs and bristles as compared to those found on the body of a normal adult; genitalia undeveloped. Pupal cuticle enveloped the entire body (Plate 2E and F).

(VIII) Pupal-adult mosaic similar to normal adult except the genitalia not fully developed and whole body enclosed in the pupal cuticle (Plate 2G-I).

Different grades of pupal-adult mosaics produced as a result of treatment of 0-3-day-old third instar larvae with different doses of root extracts of $W$. somnifera have been shown in Fig. 3. Pupal-adult 

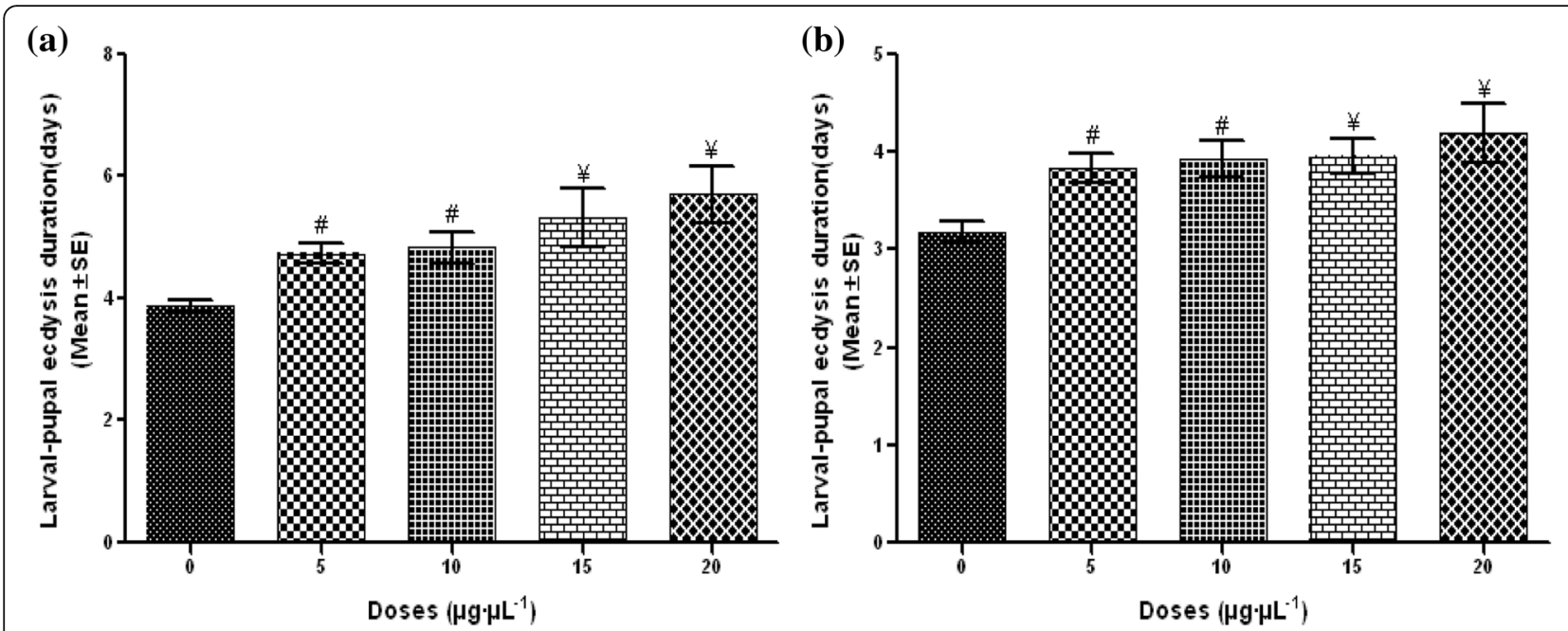

(c)
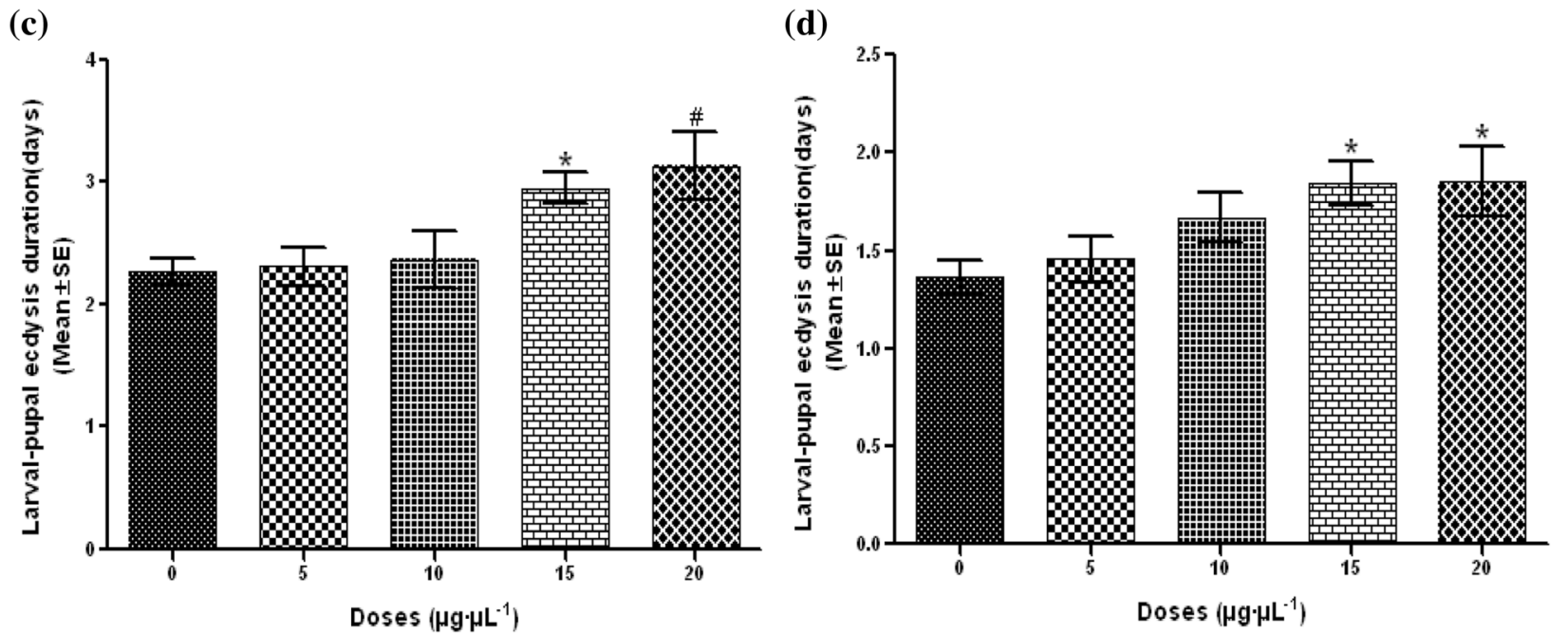

Fig. 2 Larval-pupal ecdysis duration (days) after topical administration of root extracts $W$. somnifera to a third instar day 0 larvae, $\mathbf{b}$ third instar day 1 larvae, $\mathbf{c}$ third instar day 1 larvae, and $\mathbf{d}$ third instar day 3 larvae of S. ruficornis. ${ }^{*}$ Significant at $p \leq 0.05$; \#Significant at $p \leq 0.01$; ${ }^{*}$ Significant at $p \leq 0.001$

mosaics of grades I, II, III, and IV were produced in case of treatment of 0-1-day-old last instar larvae (Fig. 3a, b), whereas those of grades V, VI, VII, and VIII were produced when 2-3-day-old third instar larvae were treated (Fig. 3c, d).

\section{Adult emergence}

Topical administration of W. somnifera root extracts to third instar 0-3-day larvae of S. ruficornis resulted into a reduction in adult emergence showing a negative correlation between the doses administered and the percentage of adult emergence in a dose-dependent manner (Table 1). The normal adult emergence was totally suppressed at a dose of $20 \mu \mathrm{g} / \mu \mathrm{L}$ of root extracts in all the cases of treatment (Table 1 ).

\section{Adultoids}

Topical administration of root extracts of $W$. somnifera to third instar 0-3-day-old larvae of S. ruficornis resulted in the emergence of adultoids.

Depending upon the morphological abnormalities, the adultoids have been classified into the following types:

(1) Adultoid with deformed wings, unable to stretch; deformed and partially tanned legs; abdomen reduced with black pigmentation as compared to light and dark square dots present on the abdomen of a normal adult; scar of genitalia developed (Plate $2 \mathrm{~K}$ and $\mathrm{L}$ ).

(2) Adultoid with deformed wings unable to inflate; ptilinum everted; legs deformed, twisted and not suitable to sit or walk; a few hairs and bristles 


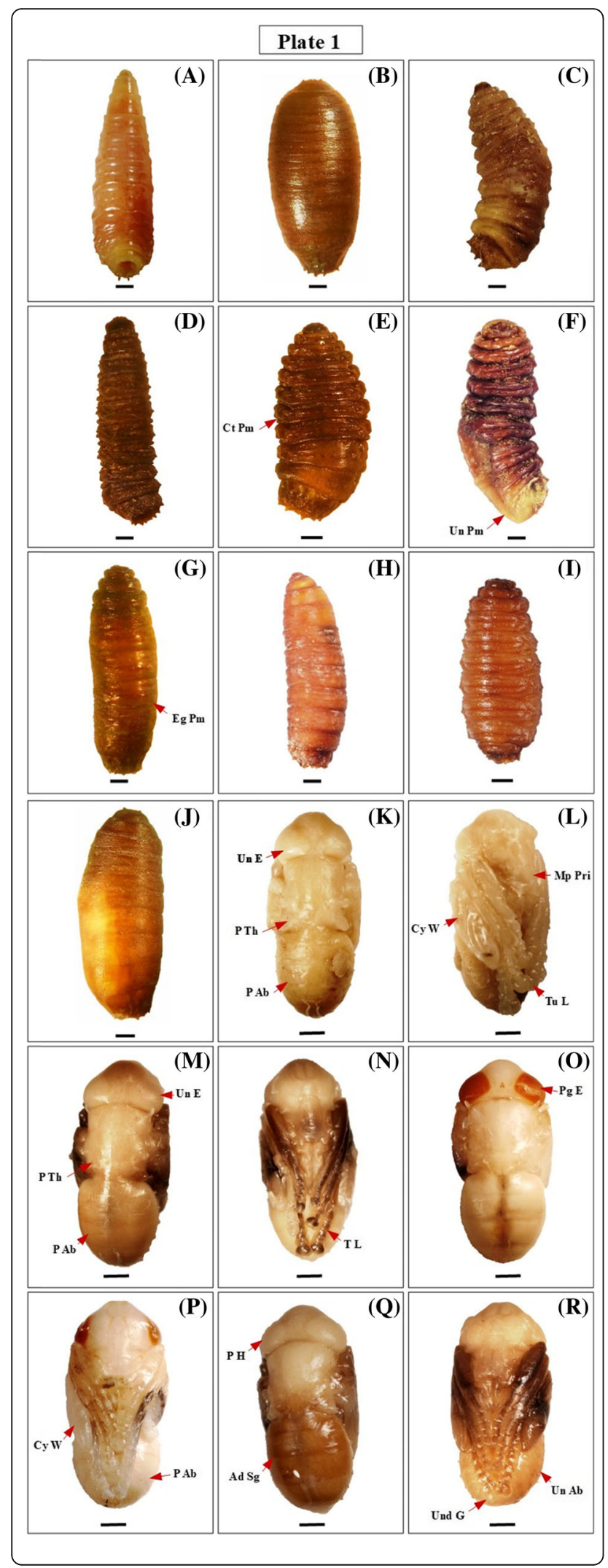

Plate 1 Types of deformities produced after topical administration of root extracts of Withania somnifera to 0-3-day-old third instar larvae of Sarcophaga ruficornis. (A) Normal third instar larva. (B) Normal puparium. (C) Abnormal puparium, $10 \mu \mathrm{g} / \mu \mathrm{L}$, third instar day 0. (D) Abnormal elongated puparium, $5 \mu \mathrm{g} / \mu \mathrm{L}$, third instar day 1. (E) Abnormal contracted puparium, $20 \mu \mathrm{g} / \mu \mathrm{L}$, third instar day 2. (F) Twisted puparium with unsclerotized posterior part of body, $15 \mu \mathrm{g} /$ $\mu \mathrm{L}$, third instar day 3. (G) Abnormal elongated puparium, $10 \mu \mathrm{g} / \mu \mathrm{L}$, third instar day 2. (H) Abnormal puparium with light brown pupal pigmentation, $15 \mu \mathrm{g} / \mu \mathrm{L}$, third instar day 3. (I) Abnormal puparium with light brown pupal pigmentation, $20 \mu \mathrm{g} / \mu \mathrm{L}$, third instar day 0 . (J) Abnormal puparium, $5 \mu \mathrm{g} / \mathrm{\mu L}$, third instar day 2. (K, L) Dorsal and ventral view of pupal-adult mosaic grade I, $15 \mu \mathrm{g} / \mu \mathrm{L}$, third instar day 0. $(M, N)$ Dorsal and ventral view of pupal-adult mosaic grade II, 20 $\mu \mathrm{g} / \mu \mathrm{L}$, third instar day 1. $(\mathrm{O}, \mathrm{P})$ Dorsal and ventral view of pupaladult mosaic grade III, $5 \mu \mathrm{g} / \mu \mathrm{L}$, third instar day 0 . (Q, R) Dorsal and ventral view of pupal-adult mosaic grade IV, $10 \mu \mathrm{g} / \mu \mathrm{L}$, third instar day 1. (Bar $=1 \mathrm{~mm}$; red arrow pointing out the deformities. $\mathrm{Ad} \mathrm{Sg}=$ adult segmentation, $\mathrm{Ct}$ Pm = contracted puparium, Cy W = cylindrical wings, Eg Pm = elongated puparium, $\mathrm{Mp}$ Pri $=$ mouthparts primordial, $\mathrm{P} \mathrm{Ab}=$ pupal abdomen, $\mathrm{P} \mathrm{H}=$ pupal head $\mathrm{P}$ $\mathrm{Th}=$ pupal thorax, $\mathrm{Pg} E=$ pigmented eyes, $\mathrm{T} \mathrm{L}=$ tanned legs, $\mathrm{Tu} \mathrm{L}$ $=$ tubular legs, Un Ab = untanned abdomen, Un E = untanned eyes, Un Pm = untanned puparium, Und G = undeveloped genitalia)

present on the posterior part of dorsal abdomen; genitalia deformed (Plate $2 \mathrm{M}$ and $\mathrm{N}$ )

(3) Adultoid with highly malformed legs and crumpled wings (Plate 2O)

(4) Adultoid with deformed body unable to eclose from the puparium (Plate 2P and Q). In some cases, the puparium remained attached to the metathoracic leg (Plate 2R).

\section{Discussion}

Topical administration of different doses of root extracts of W. somnifera to 0-3-day-old last instar larvae of $S$. ruficornis resulted into larval and pupal mortality, delay in larval-pupal ecdysis, abnormal pupariation, suppression of adult emergence, and formation of pupal-adult mosaics and adultoids.

Topical treatment of 0-3-day-old larvae of S. ruficornis with different doses of root extracts of W. somnifera produced larval and pupal mortality in a dose-dependent manner. The toxic effect of root extracts of this medicinal plant has also been observed when the larvae of dipteran insects such as Anopheles stephensi (Diptera: Culicidae), Aedes aegypti, and Culex quinquefasciatus are treated (Bansal et al. 2011). Apart from dipterans, the larvae and pupae of coleopterans and lepidopterans are also susceptible to root extracts of $W$. somnifera (Arora et al. 2011; Gaur and Kumar, 2017a, 2019) showing its broad-spectrum insecticidal activity. In the present study, it has been observed that freshly moulted third instar larvae (0-day old) are highly susceptible to treatment with root extracts as compared to older larvae as maximum toxicity has been observed in case of 


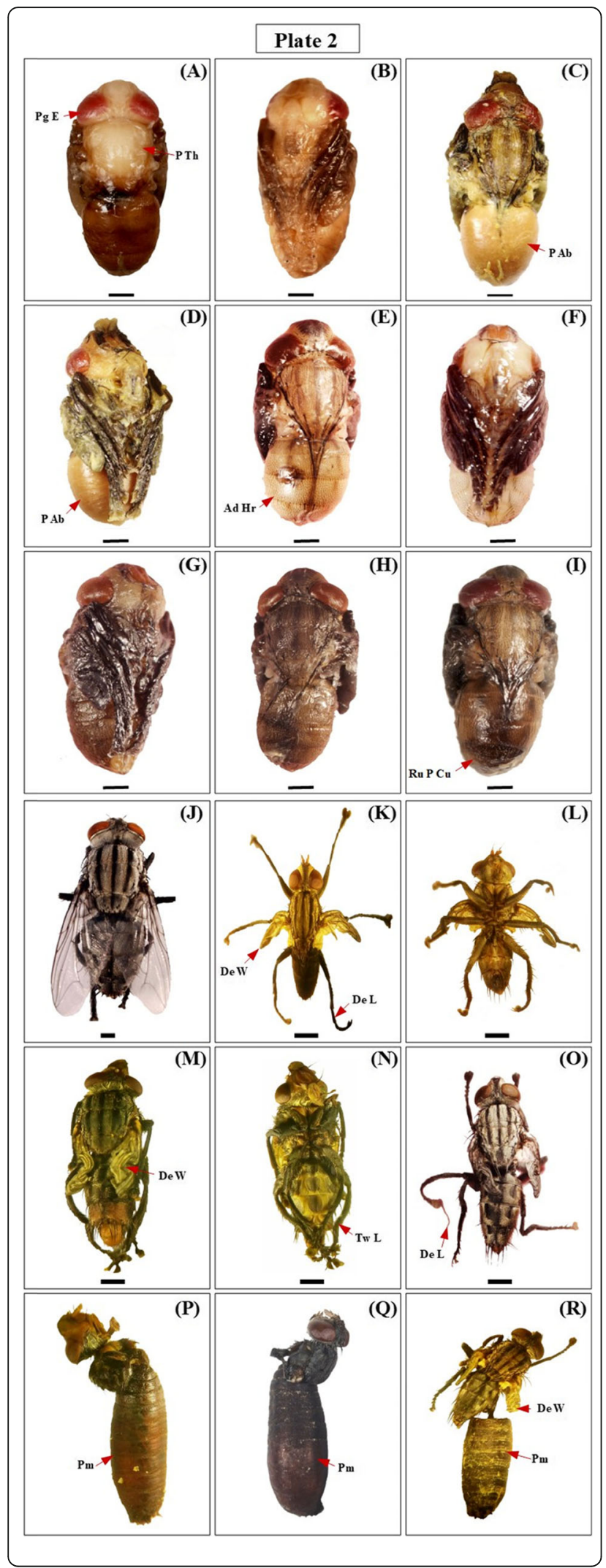

Plate 2 Types of deformities produced after topical administration of root extracts of Withania somnifera to 0-3-day-old third instar larvae of Sarcophaga ruficornis. (A, B) Dorsal and ventral view of pupal-adult mosaic grade $\mathrm{V}, 5 \mu \mathrm{g} / \mu \mathrm{L}$, third instar day 2. (C, D) Dorsal and ventral view of pupal-adult mosaic grade $\mathrm{Vl}, 10 \mu \mathrm{g} / \mathrm{\mu L}$, third instar day 3. (E, F) Dorsal and ventral view of pupal-adult mosaic grade $\mathrm{VII}, 20 \mathrm{\mu g} / \mathrm{\mu L}$, third instar day 2. $(\mathrm{G}, \mathrm{H})$ Dorsal and ventral view of pupal-adult mosaic grade VIII, $15 \mu \mathrm{g} / \mu \mathrm{L}$, third instar day 3. (I) Dorsal view of pupal-adult mosaic grade VIII, $5 \mu \mathrm{g} / \mu \mathrm{L}$, third instar day 2. (J) Dorsal view of normal adult. (K, L) Dorsal and ventral view of adultoid with deformed wings and legs, $20 \mu \mathrm{g} / \mu \mathrm{L}$, third instar day 0 . $(M, N)$ Dorsal and ventral view of adultoid with deformed wings and twisted legs, $5 \mu \mathrm{g} / \mu \mathrm{L}$, third instar day 1. (O) Dorsal view of adultoid with crumpled wings, $15 \mu \mathrm{g} / \mu \mathrm{L}$, third instar day 2. (P) Lateral view of adultoid unable to eclose from the puparium, $10 \mu \mathrm{g} /$ $\mu \mathrm{L}$, third instar day 3. (Q) Lateral view of adultoid unable to eclose from the puparium, $15 \mu \mathrm{g} / \mu \mathrm{L}$, third instar day 0 . (R) Doral view of adultoid with puparium, $20 \mathrm{\mu g} / \mu \mathrm{L}$, third instar day 1 . (Bar $=1 \mathrm{~mm}$; red arrow pointing out the deformities. $\mathrm{Ad} \mathrm{Hr}=$ adult hairs, $\mathrm{De} \mathrm{L}=$ deformed legs, De $\mathrm{W}=$ deformed wings, $\mathrm{P}$ Ab $=$ pupal abdomen, $\mathrm{P}$ $\mathrm{Th}=$ pupal thorax, $\mathrm{Pg} \mathrm{E}=$ pigmented eyes, $\mathrm{Pm}=$ puparium, $\mathrm{Ru} \mathrm{PCu}$ = ruptured pupal cuticle, Tw $L=$ twisted legs)

treatment of younger larvae. This is comparable with similar findings when Aedes albopictus larvae are treated with an insect growth regulator and a chitin synthesis inhibitor, dimilin (Ho et al. 1987). This toxicological effect could be due to the presence of certain phyto-active ingredients like withaferins and withanolides in the root extracts of W. somnifera (Dar et al. 2015).

Topical administration of root extracts of W. somnifera to last instar day 0-3 larvae of S. ruficornis significantly increased the life span of last instar larvae in a dose-dependent manner causing postponement of pupariation. The younger larvae (day 0 or 1 ) are highly susceptible in this regard as compared to older larvae (day 2 or 3 ) as the maximum effect has been observed in the former case. Plant extracts from different families of angiosperm plants have been observed to increase larval and pupal duration when administered to developmental stages of dipteran insects such as leaves extracts of Pelargonium citrosa (Geraniaceae) to fourth instar larvae of A. stephensi (Jeyabalan et al. 2003); leaves extracts of Dysoxylum malabaricum (Meliaceae) to eggs of A. stephensi (Nathan et al. 2006a); leaves and seed extracts of Melia azedarach (Meliaceae) to eggs of A. stephensi (Nathan et al. 2006b); leaves extracts of Artemisia annua L. (Asteraceae) to eggs of A. stephensi (Sharma et al. 2006b); leaves extracts of Carica papaya (Caricaceae) to fourth instar larvae of $C$. pipiens pipiens (Olayemi et al. 2013).

Such prolongation in the life span of the developmental stages of dipteran insects is similar to those that have been observed by the administration of insect growth regulators (IGRs)/juvenile hormone analogs (JHAs). For instance, IGRs buprofezin, hexaflumuron, lufenuron 

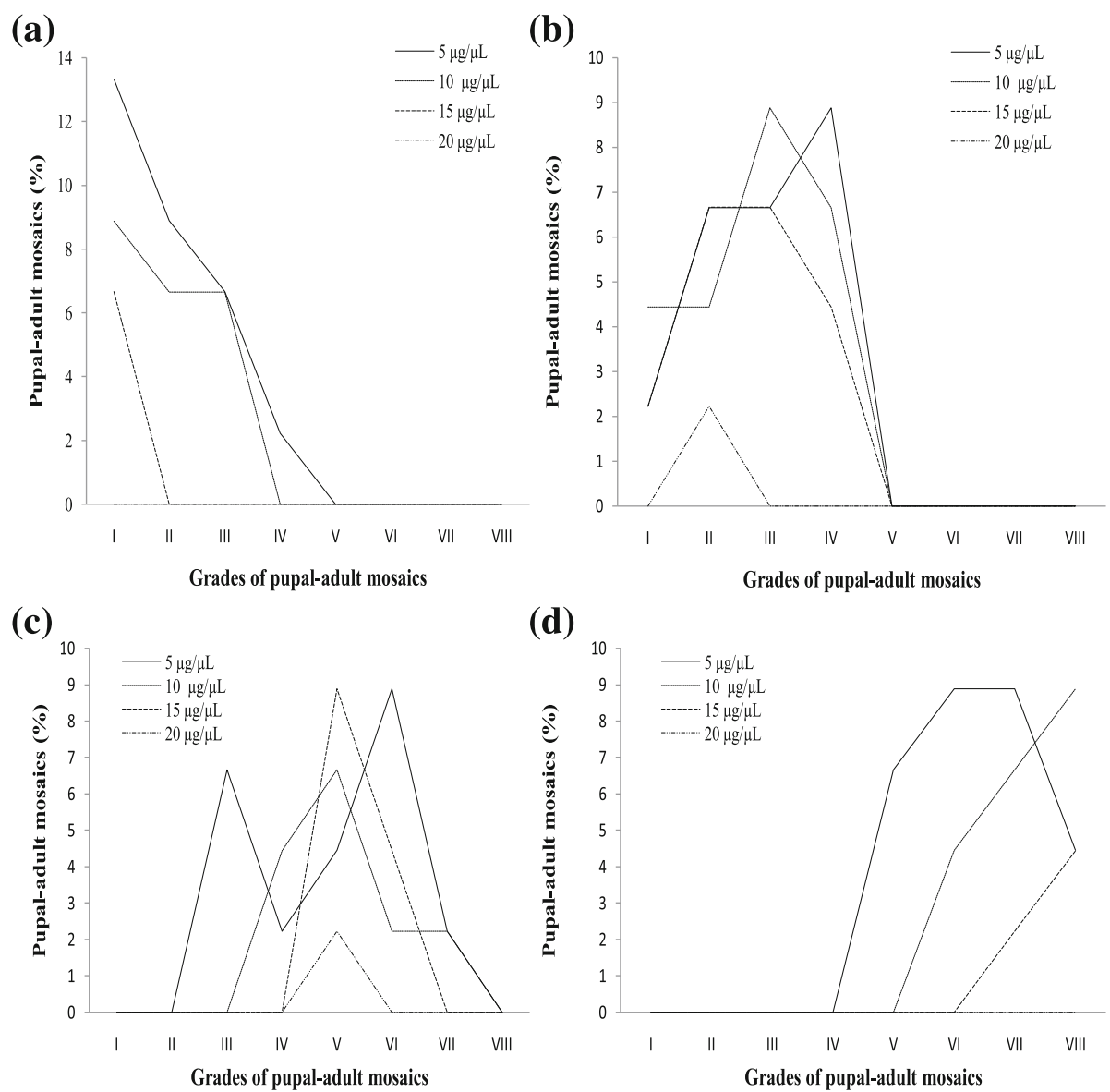

Fig. 3 Different grades of pupal-adult mosaics produced by the treatment of a 0-day-old third instar larvae, b 1-day-old third instar larvae, c 2day-old third instar larvae, and $\mathbf{d}$ 3-day-old third instar larvae of S. ruficornis with root extracts of W. somnifera

(chitin synthesis inhibitors), and JHA (pyriproxyfen) caused prolongation of larval and pupal duration in Musca domestica (Diptera: Muscidae) (Abo El-Mahasen et al. 2010). Similarly, JHAs have been reported to cause prolongation of larval and pupal duration in dipteran insects such as kinoprene in C. pipiens (Hamaidia and Soltani, 2014), pyriproxyfen in Drosophila melanogaster (Diptera: Drosophilidae) (Bensebaa et al. 2015); methoprene in Parasarcophaga argyrostoma (Diptera: Sarcophagidae) (Bakr and Tanani, 2018). This clearly demonstrates that root extracts of W. somnifera act as insect growth regulators and mimic the action of JHAs/ juvenoids. Such kind of prolongation of the life span of last instar larvae or postponement of pupariation/pupation may be due to inhibition of moulting process caused by an increased titre of juvenile hormone in the insect body (Lapcharoen et al. 2005). Administration of JHAs like DL-juvenile hormone (DL-methyl trans, trans, cis-10-epoxy-7-ethyl-3,11 dimethyl-2,6-tridecadienoate) and $\mathrm{C}_{17}$ methyl ester (methyl trans, trans, cis-7-ethyl-3, 11-dimethyl-2,6,10-tridecatrienoate) to last larval instar of $S$. bullata caused prolongation of larval life and subsequent delay in puparium formation. These effects may be due to presence of juvenile hormone in the insect body at an inappropriate time and it exerts inhibitory effect on the secretion/synthesis of moulting hormone (ecdysone) either by directly inhibiting the ecdysial glands (prothoracic glands) or by indirectly preventing the secretion of brain hormone (Srivastava and Gilbert, 1969). During the normal development, JH is responsible to regulate the action of ecdysone and 20hydroxyecdysone (20E) and a high titre of JH prevents these two hormones in causing a switch from the larval to pupal or pupal to adult differentiation (Riddiford, 1994, 1996). If the JH is exogenously applied during this critical period, this switch in the differentiative program will not take place (Riddiford et al. 2003). Thus, prolongation in the life span of developmental stages may be due to alteration in ecdysteroids titer and interruption of 20E action (Suzuki et al. 2010). There are two $\mathrm{JH}$-sensitive periods during the last instar larvae, first controls larval-pupal and second controls pupal-adult development. If $\mathrm{JH}$ is present during these sensitive periods, the current developmental state will be maintained 
and no developmental switch or differentiation to the next developmental stage will take place (Nijhout, 1998).

Topical administration of root extracts of W. somnifera to last instar 0-3-day-old larvae of S. ruficornis inhibited the puparium formation in varying degrees. This kind of effect has also been observed with various plant extracts and oils when applied to dipteran insects such as plant oils from Trigonella foenum-graecum, Apium graveolens, Raphanus sativus, Brassica compestris to third instar larvae of Lucilia sericata (Diptera: Calliphoridae) (Khater and Khater, 2009) and leave extracts from the plants Aloe zebrine and Erythrina lysistemon to second or third instar larvae of Lucilia cuprina and Chrysomya marginalis (Diptera: Calliphoridae) (Mukandiwa et al. 2012a). It is remarkable that the abnormal pupariation in S. ruficornis as a result of the treatment of third instar larvae with root extracts of W. somnifera and that observed with plant extracts and plant oils are similar to those observed with the administration of IGR/JHAs. It has been observed that the administration of IGR/JHAs produces similar effects as reported in the present case, for example, IGR cyromazine [larvadex (n-cyclopropyl-1,3,5-triazine-2,4,6-triamine)] induces abnormal pupariation as a result of treatment of third instar larvae of $M$. domestica (Awad and Mulla, 1984). JHAs such as methyl 10,11-epoxy-3,7, 11-trimethyl-2,6-tridecadienoate, isopropyl 11-chloro3,7,11-trimethyl-2-dodecanoate, and isopropyl 11methoxy-3,7,11-trimethyl-2,4-dodecadienoate produce similar effect in Musca, Sarcophaga, Ceratitis, Calliphora spp (Sehnal and Zdarek, 1976). Besides JH agonist, pyriproxyfen application to eggs of C. megacephala also caused the formation of abnormal puparia (Singh and Kumar, 2015b).

In cyclorrhaphous diptera, the larval cuticle of the last larval instar, unlike the lepidopteran insects, is not shed at the larval-pupal moult and rather it is retained as a hard protective covering called puparium. There are several steps involved in the puparium formation such as retraction of anterior larval segments, longitudinal body contraction and cuticular shrinkage leading to a smooth, barrel-shaped and sclerotized body. The hormones involved in puparium formation are anterior segment retraction factor (ARF), puparium-immobilizing factor (PIF), and puparium tanning factor (PTF). These are proteinaceous neurohormones simultaneously secreted by the neurosecretory cells of the central nervous system (Sivasubramanian et al. 1974). ARF is responsible for retraction of anterior larval segments shaping the larval integument into barrel-shaped puparium. PIF causes the larvae to become immobile and the larvae become more and more sensitive to this factor as the time of normal pupariation approaches and finally, PTF is responsible for the sclerotization of the puparium (Nijhout, 1998). In the present study, all the events related with the puparium formation are adversely affected and this demonstrates that secretion/activity of all the pupariation factors such as ARF, PIF, and PTF is either suppressed or inhibited in varying degrees.

The development of pupal-adult mosaics is another prominent and conspicuous effect observed as a consequence of administration of root extracts of W. somnifera to last instar larvae of S. ruficornis. It is worthwhile to mention that younger larvae are more susceptible to $W$. somnifera root extract treatment as compared to older larvae as greater suppression of imaginal differentiation or retention of more pupal characters occurs when the former is treated. This is similar to pupal treatment of Spodoptera litura (Lepidoptera: Noctuidae) with a juvenoids (6, 7-epoxy-3-ethyl-1 (p-ethyl phenoxy)-7 methylnonane) where more pupal characters are retained in pupal-adult intermediates when younger pupae are treated (Srivastava and Prasad, 1982). Formation of mosaics (larval-pupal/pupal-adult) has also been observed as a result of treatment of developmental stages of lepidopteran insects with root extracts of $W$. somnifera, for instance, treatment of sixth instar larvae and freshly moulted 0-2-h-old pupae of S. litura (Gaur and Kumar, 2017a, 2019) and treatment of seventh instar larvae of Pericallia ricini (Lepidoptera: Arctiidae) (Gaur and Kumar, 2017b). The root extracts of a medicinal plant, Ecbolium viride contain a lignin compound, ecbolin B and this has been reported to produce larvalpupal and pupal-adult mosaics/intermediates in the dipteran insect, A. aegypti (Reegan et al. 2016). Apart from root extracts, the extracts from other parts of the plants also produce similar effects such as seed extracts of Argemone mexicana administration to second instar larvae of $A$. aegypti (Sakthivadivel and Thilagavathy, 2003), leaves extracts of Artemisia annua to third instar larvae of A. stephensi (Sharma et al. 2006a) and leaves extracts of Artemisia annua to eggs of C. quinquefasciatus (Sharma et al. 2006b).

Surprisingly, administration of IGRs/JHAs has also been observed to produce such forms of mosaics/intermediates in several dipteran insects, as observed in the present study, such as treatment with IGRs like altosid $^{\mathrm{TM}}$ (isopropyl 11-methoxy-3,7,11-trimethylododeca-2, 4-dienoate) in C. tarsalis (Arias and Mulla, 1975); $\mathrm{PH}$ 60-40 [N-(4-chlorophenyl)- $\mathrm{N}^{\prime}$-(2,6-diflurobenzoyl) urea] in Stomoxys calcitrans (Diptera: Muscidae) (Hayakawa, 1976); pyriproxyfen, novaluron and methoxyfenozoide in Bactrocera zonata (Diptera: Tephritidae) (Fahmy et al. 2013) and JHAs such as methoprene in C. moletsus and C. quinquefasciatus (Gelbic et al. 2002); pyriproxyfen in $S$. ruficornis and C. megacephala (Singh and Kumar, 2015b, c). The development of pupal-adult mosaics/intermediates may be considered as a true juvenilizing 
effect (Wright 1970; Wright and Spates, 1971). It has been suggested that the plants produce phytochemicals which may act as $\mathrm{JH}$ mimics (juvenoids) and interfere with the endocrine control of insects (Bede and Tobe, 2000) leading to disruption of normal hormonal activity of the metabolic processes in the developing stage (Sakthivadivel and Thilagavathy, 2003). There are two different developmental switches in the holometabolous insects, first during larval-pupal and second during pupal-adult moult. The developmental switches that occur during $\mathrm{JH}$ sensitive period are activated by the ecdysteroids and progress to the next developmental stage takes place when either $\mathrm{JH}$ is absent or very low during JH sensitive period (Nijhout, 1998). Thus the presence of certain bioactive plant compounds during $\mathrm{JH}$ sensitive period may interfere with the normal endocrine regulation of moulting and metamorphosis producing non-viable larval-pupal or pupal-adult mosaics/ intermediates in the same way as natural $\mathrm{JH} /$ juvenoids do (Kabir et al. 2013). In fact, the presence of JH during the critical period of development when it is not required may disrupt the hierarchy of ecdysone-mediated metamorphic change resulting in developmental aberrations (Wilson, 2004).

The pupal-adult mosaics formed as a consequence of the treatment of root extracts of $W$. somnifera show ecdysial stasis. The ecdysial failure has also been reported by the administration of other plant extracts (fruit and leaves extracts of Azadirachta indica and Melia azedarach) to dipteran insects, Lutzomyia longipalpis (Diptera: Psychodidae: Phlebotominae) (Andrade-Coelho et al. 2009), and IGR (diflubenzuron) to C. quinquefasciatus (Mulla, 1995). In an orthopteran insect, Locusta migratoria (Orthoptera: Acrididae), a phytochemical, azadirachtin induced moulting inhibition as a result of suppression of ecdysteroid titre (Sieber and Rembold, 1983). In rice weevil, Sitophils oryzae (Coleoptera: Curculionidae), treatment with JHA, hydroprene, and IGR, R-20458 caused the formation of pupal-adult intermediates which suffered from ecdysial failure and ultimately died and the effect could be due to interference with the endogenous level of $\mathrm{JH}$ during metamorphosis (Gupta and Mkhize, 1983). Moult inhibition has also been caused by a phytochemical, podophyllotoxin, which may interfere with the neuroendocrine system as a result of blocking the synthesis/release of PTTH and ecdysone (Garcia and Azambuja, 2004).

The significant reduction in normal pupariation and adult emergence as a result of treatment of last instar larvae of S. ruficornis with root extracts of W. somnifera is similar to those induced by other plant extracts (Mukandiwa et al. 2012a, b) or oils in dipteran insects (El-Khateeb et al. 2003; Khater and Khater, 2009). It has been observed that exogenous administration of JHA, pyriproxyfen to freshly laid eggs of $C$. megacephala or adults of $S$. ruficornis produced similar effects in ensuing postembryonic development or F1 generation (Singh and Kumar 2015b, c). This clearly demonstrates that the plant extracts mimic the action of JH/JHA as the juvenoids are well known to inhibit/suppress the pupation (Eto, 1990; Nakakita, 1982, 1990) and adult emergence due to reduction or interference with the secretion of eclosion hormone (Ghoneim et al. 2007).

The formation of adultoids is another very prominent effect induced by $W$. somnifera root extracts, and it is a manifestation of hormonal imbalance as a result of interference with the endocrine system. This has also been observed as a result of the treatment of dipteran larvae with others plant extracts (Mwangi and Mukiama, 1988; Kabir et al. 2013)/their secondary metabolites (Sharma and Sohal, 2013, 2015) and active ingredients (Reegan et al. 2016). It is interesting that similar effect has also been observed as a result of administration of JHA, pyriproxyfen to dipteran insects, D. melanogastor (Bensebaa et al. 2015), C. megacephala (Diptera: Calliphoridae) (Singh and Kumar, 2015b), and S. ruficornis (Singh and Kumar, 2015c). It has been suggested that plant extracts mimic the action of JH (Munoz et al. 2013) which may affect the development of imaginal structures (Riddiford and Ashburner, 1991) as the JH/JHA are well known to inhibit proliferation of imaginal disc cells (Oberlander et al. 2000). There is an additional JH sensitive period during the initial phase of the pupal stage during which $\mathrm{JH}$ must be absent to allow the epidermal cells to proceed for imaginal development and differentiation and if the JHA (pyriproxyfen) is present during this critical period this may result into deformed adults or reduction in adult emergence (Nijhout, 1998; Bensebaa et al. 2015). In the present study, some of the adultoids were unable to extricate from the puparium and this shows that the secretion/activity of the eclosion hormone is interfered with as it is responsible for freeing the adult body from the puparium. Such kind of detrimental effect on the eclosion behavior has also been observed as a result of administration of plant oils from two medicinal plants, Cymbopogon citrates and Syzygium aromaticum to dipteran insects, $A$. aegypti and $A$. dirus (Soonwera and Phasomkusolsil, 2016). Besides IGRs such as cyromazine (Moreno-Mari et al. 1996) and novaluron (Fahmy et al. 2013) and JHA, pyriproxyfen produce similar effect in dipteran insects (Singh and Kumar, 2015c). This demonstrates that root extracts of W. somnifera possess IGR activity and mimic the action of JH/ JHA that adversely affect the secretion/release of a neuropeptide eclosion hormone responsible for the eclosion of an adult from the puparium and bursicon responsible for the sclerotization and tanning and the effects can be compared by the administration of JHAs, 
pyriproxyfen, and diofenolan, to last instar larvae of $S$. litura (Singh and Kumar, 2015a).

\section{Conclusion}

Therefore, root extracts of W. somnifera may be used as a potential insect growth regulator for the control and management of myiasis causing flesh fly S. ruficornis along with other bio-rational approaches.

\section{Acknowledgements}

The authors are highly grateful to the Head, Department of Zoology, University of Allahabad, Prayagraj (India), for providing laboratory assistance.

\section{Authors' contributions}

All the authors contributed equally to the experimental design, observation, manuscript preparation, and correction. Both the authors read and approved the final manuscript.

\section{Funding}

Not applicable.

\section{Availability of data and materials}

Please contact the corresponding author for data requests.

\section{Ethics approval and consent to participate}

Not applicable.

\section{Consent for publication}

Not applicable.

\section{Competing interests}

The authors declare that they have no competing interests.

Received: 9 December 2019 Accepted: 23 March 2020

Published online: 29 May 2020

\section{References}

Abo El-Mahasen, M., Assar, A., Khalil, E., \& Mahmoud, H. (2010). Biological effects of some insect growth regulators on the house fly, Musca domestica (diptera: muscidae). Egypt Academy Journal Biological Science, 3(2), 95-105.

Andrade-Coelho, C., Souza, N. A., Gouveia, C., Silva, V. C., Gonzalez, M. S., \& Rangel, E. F. (2009). Effect of fruit and leaves of meliaceae plants (Azadirachta indica and Melia azedarach) on the development of Lutzomyia longipalpis larvae (Diptera: Psychodidae: Phlebotominae) under experimental conditions. Journal of Medical Entomology, 46(5), 1125-1130.

Arias, J. R., \& Mulla, M. S. (1975). Morphogenetic aberrations induced by a juvenile hormone analogue in the mosquito Culex Tarsalis (Diptera: Culicidae). Journal of Medical Entomology, 12(3), 309-316.

Arora, M., Sharma, J., Singh, A., \& Negi, R. S. (2011). Larvicidal property of aqueous extracts of Withania somnifera on Tribolium castaneum. Indian Journal of Fundamental and Applied Life Sciences, 1(2), 32-36.

Awad, T.I., \& Mulla, M.S. (1984). Morphogenetic and histopathological effects induced bt the insect growth regulator cyromazine in Musca domestica (Diptera: muscidae). Journal of Medical Entomology, 21(4), 419-426.

Bakr, R.F.A., \& Tanani, M.A. (2018). Toxicity and physiological activity of methoprene, a juvenile hormone analog, against development and metamorphosis of the grey flesh fly, Parasarcophaga argyrostoma (RobineauDesvoidy) (Diptera: Sarcophagidae). Egypt Academy Journal Biological Science, 11(2), 1-27.

Bansal, S. K., Singh, K. V., Sharma, S., \& Sherwani, M. R. K. (2011). Comparative larvicidal potential of different plant parts of Withania somnifera against vector mosquitoes in the semi-arid region of Rajasthan. Journal of Environmental Biology, 32(1), 71-75

Bede, J.C., \& Tobe, S.S. (2000). Insect juvenile hormones in plants. Studies in Natural Products Chemistry, 22(Part C), 369-418.

Bensebaa, F., Kilani-Morakchi, S., Aribi, N., \& Soltani, N. (2015). Evaluation of pyriproxyfen, a juvenile hormone analog, on Drosophila melanogaster (Diptera: Drosophilidae): Insecticidal activity, ecdysteroid contents and cuticle formation. European Journal Entomology, 112(4), 1-7.
Dar, N. J., Hamid, A., \& Ahmad, M. (2015). Pharmacologic overview of Withania somnifera, the Indian Ginseng. Cellular and molecular life sciences, 72, 4445-4460.

El-Khateeb, R. M., Abdel-Shafy, S., \& Zayed, A. A. (2003). Insecticidal effects of neem seed and vegetable oils on larval and pupal stages of sheep blowfly, Lucilia sericata (Diptera: Calliphoridae). Journal of Egypt Veterinary and Medical Association, 63, 255-268.

Ergun, S., Akınc, O., Sirekbasan, S., \& Kocael, A. (2016). Postoperative wound myiasis caused by Sarcophaga carnaria. Turkiye Parazitol Derg, 40, 172-175.

Eto, M. (1990). Biochemical mechanism of insecticidal activities. In: Haug, G., \& Hoffman (Eds.), Chemistry of Plant Protection, $6^{\text {th }}$ edn. Springer -Verlag, Berlin, Heidelberg, pp 65-107.

Fahmy, A. R., Hassan, H. A., Negm, A. A. K. H., Mosallam, A. M. Z., El-Shafei, A. M., \& El-Naggar, M. E. (2013). Efficacy of some igrs for the control of peach fruitfly, Bactrocera zonata (Saunders) (Diptera: Tephritidae). Egyptian Journal Agricultural Research, 91(2), 561-572.

Ferraz, A. C., Proença, B., Gadelha, B. Q., Faria, L. M., Barbalho, M. G., AguiarCoelho, V. M., \& Lessa, C. S. (2010). First record of human myiasis caused by association of the species Chrysomya megacephala (Diptera: Calliplioridae), Sarcophaga (Liopygia) ruficornis (Diptera: Sarcophagidae), and Musca domestica (Diptera: Muscidae). Journal ofMedical Entomology, 47(3), 487-490.

Francesconi, F., \& Lupi, O. (2012). Myiasis. Clinical Microbiology Reviews, 25(1), 79-105.

Garcia, E. S., \& Azambuja, P. (2004). Lignoids in insects: chemical probes for the study of ecdysis, excretion and Trypanosoma cruzi - triatomine interactions. Toxicon, 44, 431-440.

Gaur, S. K., \& Kumar, K. (2017a). Bioefficacy of root extracts of a medicinal plant, Withania somnifera (Dunal) against a polyphagous pest, Spodoptera litura (Fabricius) (Lepidoptera: Noctuidae). Archives of Phytopathology and Plant Protection, 50(15-16), 802-814.

Gaur, S. K., \& Kumar, K. (2017b). Withania somnifera acts as a potential insect growth regulator in the polyphagous pest, Pericallia ricini. Journal of Plant Protection Research, 57(4), 379-388.

Gaur, S.K., \& Kumar, K. (2019). Sensitivity of tobacco caterpillar, Spodoptera litura, to extract from a medicinal plant, Withania somnifera. International Journal of Vegetable Science, doi.org/https://doi.org/10.1080/19315260.2019.1605556.

Gelbic, I., Olejnicek, J., \& Grubhoffer, L. (2002). Effects of insect hormones on hemagglutination activity in two members of the Culex pipiens complex. Experimental Parasitology, 100, 75-79.

Ghoneim, K.S., Bream, A.S., Tanani, M.A., \& Nassar, M.I. (2007). Efficacy of lufenuron (CGA-184699) and diofenolan (CGA-59205) on survival, growth and development of the red palm weevil, Rhynchophorous ferrugineus (Coleoptera: Curculionidae) (2007). In $59^{\text {th }}$ Int. Symposium on Crop Protection, Ghent, Belgium pp 246-279.

Graczyk, T. K., Knight, R., \& Tamang, L. (2005). Mechanical transmission of human protozoan parasites by insects. Clinical Microbiology Reviews, 18(1), 128-132.

Gupta, A.P., \& Mkhize, J.M. (1983). Developmental and morphogenetic effects of two insect growth regulators (hydroprene and R-20458) on the female rice weevil, Sitophilus Oryzae (L.) (Coleoptera: Curculionidae). Applied Ent Zool, 18(1), 11-21.

Gupta, L., \& Srivastava, M. (2008). Effect of Withania somnifera extracts on the mortality of Callosobruchus Chinensis L. Journal of Biopesticides, 1(2), 190-192.

Hamaidia, K., \& Soltani, N. (2014). Laboratory evaluation of a biorational insecticide, kinoprene, against Culex pipiens larvae: effects on growth and development. Annual Research and Review in Biology, 4(14), 2263-2273.

Hayakawa, H. (1976). Evaluation of PH 60-40, an insect growth regulator, for control of the stable fly Stomoxys calcitrans (L.): (Diptera, Muscidae). Jap J Sanit Zool, 27(3), 261-264.

Ho, C. M., Hsu, T. R., Wu, J. Y., \& Wang, C. H. (1987). Effect of dimilin, a chitin synthesis inhibitor, on the growth and development of larvae of Aedes albopictus skuse. Chin J Entomol, 7, 131-135.

Jeyabalan, D., Arul, N., \& Thangamathi, P. (2003). Studies on effects of Pelargonium citrosa leaf extracts on malarial vector, Anopheles stephensi Liston. Bioresource Technology, 89, 185-189.

Kabir, K.E., Choudhary, M.I., Ahmed, S., \& Tariq, R.M. (2013). Growth-disrupting, larvicidal and neurobehavioral toxicity effects of seed extract of Seseli diffusum against Aedes aegypti (L.) (Diptera: Culicidae). Ectoxicology and Environmental Safety, 90, 52-60.

Kaya, F. D., Orkun, O., Cakmak, A., Inkaya, A. C., \& Erguven, S. (2014). Cutanous myiasis caused by Sarcophaga spp. larvae in a diabetic patient. Mikrobiyol Bul, $48(2), 356-361$ 
Khater, H. F., \& Khater, D. F. (2009). The insecticidal activity of four medicinal plants against the blowfly Lucilia sericata (Diptera: Calliphoridae). International Journal of Dermatology, 48, 492-497.

Lapcharoen, P., Apiwathnasorn, C., Komalamisra, N., Dekumyoy, P., Palakul, K., \& Rongsriyam, Y. (2005). Three indigenous Thai medicinal plants for control of Aedes aegypti and Culex quinquefasciatus. Southeast Asian J Trop Med public Health, 36(4), 167-175

Ly, P., Aizenberg, A., Martin, T., Lopez, M., Saldana, M.A., Hughes, G.L., \& Cabada, M.M. (2018). Intestinal myiasis caused by Sarcophaga spp. in Cusco, Peru: a case report and review of the literature. Case Reports in Infectious Diseases, https://doi.org/https://doi.org/10.1155/2018/3685439.

Martinez-Rojano, H., Noguez, J.C., \& Huerta, H. (2018). Nosocomial myiasis caused by Lucilia sericata (Diptera: Calliphoridae) and neonatal myiasis by Sarcophaga spp. (Diptera: Sarcophagidae) in Mexico. Case Reports in Infectious Diseases, https://doi.org/https://doi.org/10.1155/2018/5067569.

Moreno-Mari, J., Echeverria-Sansano, A., \& Jimenez-Peydro, R. (1996). Cyromazine effects on Opius concolor szepl. (Hymenoptera: Braconidae) applied through laboratory host Ceratitis capitata wied. (Diptera: Tephritidae). Applied Entomology Zoology, 31(4), 525-529.

Mukandiwa, L., Eloff, J. N., \& Naidoo, V. (2012a). Evaluation of plant species used traditionally to treat myiasis for activity on the survival and development of Lucilla cuprina and Chrysomya marginalis (Diptera: Calliphoridae). Vaterinary Parasitology, 190, 566-572.

Mukandiwa, L., McGaw, L. J., Eloff, J. N., \& Naidoo, V. (2012b). Extracts of four plant species used traditionally to treat myiasis influence pupation rate, pupal mass and adult blowfly emergence of Lucilia cuprina and Chrysomya marginalis (Diptera: Calliphoridae). Journal of Ethnopharmacology, 143, 812818.

Mulla, M. S. (1995). The future of insect growth regulators in vector control. Journal of The American Mosquito Control Association, 11(2), 269-273.

Munoz, E., Lamilla, C., Marin, J. C., Alarcon, J., \& Cespedes, C. L. (2013). Antifeedant, insect growth regulatory and insecticidal effects of Calceolaria talcana (Calceolariaceae) on the Drosophila melanogaster and Spodoptera frugiperda. Industrial Crops and Products, 42, 137-144.

Mwangi, R. W., \& Mukiama, T. K. (1988). Evaluation of Melia volkensii extract fractions as mosquito larvicides. Journal of The American Mosquito Control Association, 4(4), 442-447.

Nakakita, H. (1982). Effect of larval density on pupation of Tribolium freeman Hinton (Coleoptera: Tenebrionidae). Applied Entomology Zoology, 17, 269276.

Nakakita, H. (1990). Hormonal control of inhibition of pupation caused by crowding larvae of Tribolium freeman Hinton (Coleoptera: Tenebrionidae). Applied Entomology Zoology, 25, 347-353.

Nathan, S. S., Kalaivani, K., \& Sehoon, K. (2006a). Effects of Dysoxylum malabaricum Bedd. (Meliaceae) extract on the malarial vector Anopheles stephensi Liston (Diptera: Culicidae). Bioresource Technology, 97, 2077-2083.

Nathan, S. S., Savitha, G., George, D. K., Narmadha, A., Suganya, L., \& Chung, P. G. (2006b). Efficacy of Melia azedarach L. extract on the malarial vector Anopheles stephensi Liston (Diptera: Culicidae). Bioresource Technology, 97, 1316-1323.

Nijhout, H. F. (1998). Insect Hormone, (4th ed., pp. 1-267). Princeton, NJ: Princeton University press.

Oberlander, H., Leach, C. E., \& Shaaya, E. (2000). Juvenile hormone and juvenile hormone mimics inhibit proliferation in a lepidopteran imaginal disc cell line. Journal of Insect Physiology, 46, 259-265.

Oktener, A., \& Alas, A. (2009). Cases of external myiasis caused by diptera (Sarcophaga sp.) on three cyprinid species. Reviews in Fisheries Science, 17(1), 68-69.

Olayemi, I. K., Yakubu, H., \& Ukubuiwe, A. C. (2013). Larvicidal and insect growth regulatory (IGR) activities of leaf-extract of Carica papaya against the filariasis vector mosquito, Culex pipiens pipiens (Diptera: Culicidae). Acta Biologica Malaysiana, 2(3), 100-106.

Pant, M., Dubey, S., \& Patanjali, P. K. (2016). Recent advancements in bio-botanical pesticide formulation technology development. In V. Veer, \& R. Gopalakrishnan (Eds.), Herbal Insecticides, Repellents and Biomedicines: Effectiveness and Commercialization, (pp. 117-126). New Delhi, India: Springer.

Rajapakse, R.H.S., Ratnasekera, D., Abeysinghe, S. (2016). Biopesticides research: current status and future trends in Sri Lanka. In: Agriculturally Important Microorganisms, Springer, Singapore, pp 219-234. https://doi.org/https://doi. org/10.1007/978-981-10-2576-1.
Rathi, M. J., \& Gopalakrishnan, S. (2006). Insecticidal activity of aerial parts of Synedrella nodiflora Gaertn (Compositae) on Spodoptera litura. Journal of Central European Agriculture, 6(3), 223-228.

Reegan, A. D., Gandhi, M. R., Sivaraman, G., Cecilia, K. F., Ravindhran, R., Balakrishna, K., ... Ignacimuthu, S. (2016). Bioefficacy of ecbolin A and ecdolin $B$ isolated from Ecbolium viride (Forsk.) Alston on dengue vector Aedes aegypti L. (Diptera: Culicidae). Parasite Epideriology and Control, 1, 78-84.

Riddiford, L. M. (1994). Cellular and molecular actions of juvenile hormone. I. General considerations and premetamorphic actions. Advance Insect Physiology, 24, 213-274.

Riddiford, L. M. (1996). Molecular aspects of juvenile hormone action in insect metamorphosis. In L. I. Gilbert, J. R. Tata, \& B. G. Atkinson (Eds.), Metamorphosis: postembryonic reprogramming of gene expression in amphibian and insect cells, (pp. 223-251). San Diego: Academic Press.

Riddiford, L.M., \& Ashburner, M. (1991). Effects of juvenile hormone mimics on larval development and metamorphosis of Drosophila melanogaster. General and Comparative Endocrinology, 82(2), 172-183.

Riddiford, L. M., Hiruma, K., Zhou, X., \& Nelson, C. A. (2003). Insights into the molecular basis of the hormonal control of molting and metamorphosis from Manduca sexta and Drosophila melanogaster. Insect Biochemistry and Molecular Biology, 33(12), 1327-1338.

Sakthivadivel, M., \& Thilagavathy, D. (2003). Larvicidal and chemosterilant activity of the acetone fraction of petroleum ether extract from Argemone mexicana L. seed. Bioresource Technology, 89, 213-216.

Sehnal, F., \& Zdarek, J. (1976). Action of juvenoids on the metamorphosis of cyclorrhaphous diptera. Journal of Insect Physiology, 22, 673-682.

Sharma, P., Mohan, L., \& Srivastava, C. N. (2006a). Growth inhibitory nature of Artemisia annua extract against Culex quinquefasciatus (Say). Journal of AsiaPacific Entomology, 9(4), 389-395.

Sharma, P., Mohan, L., \& Srivastava, C. N. (2006b). Phytoextract-induced developmental deformities in malaria vector. Bioresource Technology, 97, 1599-1604.

Sharma, R., \& Sohal, S. K. (2013). Toxicity of gallic acid to melon fruit fly, Bactrocera curcurbitae (Coquillett) (Diptera: Tephritidae). Archives of Phytopathology and Plant Protection, 46(17), 2043-2050.

Sharma, R., \& Sohal, S. K. (2015). Bioefficacy of rutin against Bactrocera cucurbitae (Diptera: Tephritidae), an economically important pest of cucurbits. Journal of tropical Asian entomology, 4(1), 11-19.

Sieber, K. P., \& Rembold, H. (1983). The effects of azadirachtin on the endocrine control of moulting in Locusta migratoria. Journal of Insect Physiology, 29(6), 523-527.

Singh, S., \& Kumar, K. (2015a). Comparative efficacy of phenoxy derivative JHAs pyriproxyfen and diofenolan against polyphagous pest Spodoptera litura (Fabricius) (Noctuidae: lepidoptera). Phytoparasitica, 43(4), 553-563.

Singh, S., \& Kumar, K. (2015b). Effect of juvenoids pyriproxyfen and diofenolan on embryogenesis and postembryonic development of blow fly Chrysomya megacephala (Diptera: Calliphoridae) following egg treatment. Parasitol Res, $114,3213-3222$.

Singh, S., \& Kumar, K. (2015c). Effect of juvenoids pyriproxyfen on reproduction and $\mathrm{F} 1$ progeny in myiasis causing flesh fly sarcophaga ruficornis $\mathrm{L}$. (Sarcophagidae: Diptera). Parasitology Research, 114(6), 2325-2331.

Sivasubramanian, P., Friedman, S., \& Fraenkel, G. (1974). Nature and role of proteinaceous hormonal factors acting during puparium formation in flies. Biological Bulletin, 147, 163-185.

Soonwera, M., \& Phasomkusolsil, S. (2016). Effect of Cymbopogon citratus (lemongrass) and Syzygium aromaticum (clove) oils on the morphology and mortality of Aedes aegypti and Anopheles dirus larvae. Parasitology Research, $115,1691-1703$.

Srivastava, U. S., \& Gilbert, L. I. (1969). The influence of juvenile hormone on the metamorphosis of Sarcophaga bullata. Journal of Insect Physiology, 15, 177-189.

Srivastava, U. S., \& Prasad, S. S. (1982). A study of pupal-adult intermediates produced with juvenoid treatment of Spodoptera litura Fabr. pupae. Proc Indian Acad Sci (Anim Sci), 91(4), 337-348.

Suzuki, T., Sakurai, S., \& Iwami, M. (2010). Juvenile hormone delays the initiation of rectal sac distention by disrupting ecdysteroids action in the silkworm, Bombyx mori. Pesticide Biochemistry and Physiology, 97, 199-203.

Wilson, T. G. (2004). The molecular site of action of juvenile hormone and juvenile hormone insecticides during metamorphosis: how these compounds kill insects. Journal of Insect Physiology, 50, 111-121.

Wright, J. E. (1970). Hormones for control of livestock arthropods. Development of an assay to select candidate compounds with juvenile hormone activity in the stable fly 1. Journal of Economic Entomology, 63(3), 878-883. 
Wright, J. E., \& Spates, G. E. (1971). Biological evaluation of juvenile hormone compounds against pupae of the stable fly. Journal of agricultural and food chemistry, 19(2), 289-290.

Yadav, D. P., Kumar, M., \& Jamal, M. A. (2019). Larvicidal \& Juvenomimetic property of Withania somnifera extracts against larvae of Tribolium confusum Duavl. International Journal of Research and Analytical Reviews, 6(1), 559-563.

Zacharia, J. T. (2011). Ecological Effects of Pesticides. In: Stycheva M (ed)

Pesticides in the Modern World - Risk and Benefits. InTech, pp 129-142. https://doi.org/10.5772/949.

\section{Publisher's Note}

Springer Nature remains neutral with regard to jurisdictional claims in published maps and institutional affiliations.

Submit your manuscript to a SpringerOpen ${ }^{\odot}$ journal and benefit from:

- Convenient online submission

Rigorous peer review

- Open access: articles freely available online

High visibility within the field

- Retaining the copyright to your article

Submit your next manuscript at $\boldsymbol{\wedge}$ springeropen.com 